\title{
EDITORIAL
}

\section{Assisted Living or Facility?}

DOI:http://dx.doi.org/10.5770/cgj.17.125

We are pleased to present the first issue of the Canadian Geriatrics Journal for 2014. This issue addresses a wide variety of issues, including medical education, the relationship between urinary tract infections and delirium, and an analysis of which patients are admitted to a facility versus assisted living.

The role of assisted living in providing functional support for older adults is a growing, but relatively unexamined area of research. Rockwood et al. ${ }^{(1)}$ have provided a crosssectional analysis of which factors and events predispose patients to be admitted to assisted living versus facility care. The underlying assumption of most physicians is that assisted living is just for the "worried well", but the findings by Rockwood et al. show that assisted living is playing a role in discharge planning for much sicker and frailer patients.

Another area of concern is the growing population of older adults who are either current or former illicit drug users. Dr. Sztramko and his co-investigators ${ }^{(2)}$ have examined the demographic characteristics and health utilization behaviours in older adults in Canada's most impoverished community (Vancouver's Downtown Eastside).

Rounding out our issue, Haque et al..$^{(3)}$ prospectively examined the ability of a Clinical Skills Day to change medical students attitudes about caring for older adults, and Balogun et al. ${ }^{(4)}$ has performed a systematic review that formally examines the relationship between urinary tract infections and delirium. We are also delighted to include a summary of the recent Geriatric Psychiatry meeting, ${ }^{(5)}$ as well as presenting the abstracts for the Geriatric Psychiatry scientific sessions. ${ }^{(6)}$

Thanks, again, for all of your support!

Ken Madden, MD, MSc, FRCP(C) Editor-In-Chief, Canadian Geriatrics Journal

\section{REFERENCES}

1. Rockwood J, Richard M, Garden K, et al. Precipitating and predisposing events and symptoms admission to assisted living or nursing home care. Can Geriatr J. 2014;17(1):16-21.

2. Sztramko R, Feng C, Kerr T, et al. Demographics, healthcare utilization, and substance use profiles of older adults in Canada's lowest income neighbourhood. Can Geriatr J. 2014;17(1):5-11.

3. Haque A, Soong D, Wong C. Assessing the impact of a Geriatric Clinical Skills Day on medical students' attitudes toward geriatrics. Can Geriatr J. 2014;17(1):12-15.

4. Bolagon SA, Philbrick JT. Delirium, a symptom of UTI in the elderly: fact or fable? a systematic review. Can Geriatr J. 2014;17(1):22-26.

5. Ismail Z, Fischer C. Emerging concepts in geriatric psychiatry: an update on the Canadian Academy of Geriatric Psychiatry Annual Scientific Meeting. Can Geriatr J. 2014;17(1):2-4.

6. Fischer C. Canadian Academy of Geriatric Psychiatry 2013 Annual Scientific Meeting Abstracts. Can Geriatri J. 2014;17(1):27-36. 